\title{
Clinical Profile and Risk Factors of Patients in Stroke: A Cross- Sectional Study
}

\author{
Ramesh Raj Acharya ${ }^{1}$, Nikunja Yogi ${ }^{2}$, Susmita Khadka ${ }^{3}$, Dipak Kunwar ${ }^{4}$, Rajyashree Kunwar ${ }^{5}$, \\ Rakshya Shrestha $^{6}$, Adhyashree Karki ${ }^{7}$ \\ ${ }^{1}$ Department of Medicine. Manipal College Medical Sciences, Pokhara, Nepal. \\ ${ }^{2}$ Department of Neurosurgery, Manipal College Medical Sciences, Pokhara, Nepal. \\ ${ }^{3}$ Department of Psychiatry, Interfaith Medical Center, Brooklyn, New York, USA \\ ${ }^{4}$ Department of Psychiatry, Kathmandu University School of Sciences, Dhulikhel,Kavre, Nepal \\ ${ }^{5}$ National Center for AIDS and STD Control, save the children, Nepal. \\ ${ }^{6}$ Institute of Medicine, Maharajgunj, Kathmandu, Nepal \\ ${ }^{7}$ Department of Gastroenterology, College of Medical Sciences, Bharatpur, Nepal.
}

\author{
Correspondence: \\ Dr.Ramesh Raj Acharya \\ Lecturer, Department of Medicine. \\ Manipal College of Medical Sciences, Pokhara, Nepal. \\ Phone-9856039739 \\ E-mail: acharyaramesh555@gmail.com
}

\begin{abstract}
Background:In the last few decades, the incidence of stroke has doubled in low- and middle-income countries, whereas, during the same period stroke incidence has declined by $42 \%$ in high-income countries. The major type of stroke is ischemic, which occurs in about $87 \%$ of all stroke cases. According to the Global Burden of Disease (GBD) study in 2010, out of 11 million ischemic strokes occurred, among them, 63\% were from a low- and middle-income country. The present study aimed to investigate the clinical presentation and risk factors of stroke patients. Materials and methods: This is a descriptive cross-sectional study. Proforma was designed for socio-demographic factors and common risk factors for stroke. A Chi-square test was conducted for a bivariate relationship between clinical presentation and stroke type. Results: Altogether 50 participants were included in the study. Among them, 58\% were age 65 and over,36\% belonged to the age group 45 to 65 years and $6 \%$ belonged to the age group less than 45 years. Among the risk factors, the most common risk factor was hypertension (50\%). Among the clinical presentation aphasia (46\%) was the most common presentation, whereas, gait abnormality $(6 \%)$ and eye gaze impairment $(6 \%)$ were the least common presentation. Headache and speech abnormality was significantly associated with stroke type. Conclusion:Headache and speech abnormality are significantly associated with different types of stroke.
\end{abstract}

Key words: Headache, Hypertension, Risk factors, Speech, Stroke

$\mathrm{W}$ orldwide cerebrovascular accident (stroke) is the second leading cause of death and the third leading cause of disability. ${ }^{1}$ Globally, $70 \%$ of strokes and $87 \%$ of both stroke-related deaths and disability-adjusted life years occur in low- and middle-income countries. 2 In the last few decades, the incidence of stroke has doubled in low- and middle-income countries during the same period stroke incidence have declined by $42 \%$ in high-income countries. ${ }^{2,3}$

The major type of stroke is ischemic, which occurs in about $87 \%$ of all stroke cases. ${ }^{4}$ According to the Global Burden of Disease (GBD) study in 2010, out of 11 million ischemic strokes, $63 \%$ were from low- and middle-income countries. Also, nearly 3 million deaths occurred due to ischemic stroke. ${ }^{5}$ In Nepal, a study from Pandit A et al reported that 50,000 people per year are afflicted with stroke with 15,000 deaths annually due to stroke. ${ }^{6}$

There is limited literature on stroke from Nepal. We seem to lack a nationwide community study where almost all of the studies seem to be hospitalbased. Devkota et al. showed $68.1 \%$ of patients had an ischemic stroke, with hemorrhagic stroke being $(31.9 \%){ }^{7} \mathrm{~A}$ retrospective study of stroke patients $(n=683)$ was conducted in the neurology 
department of the Institute of Medicine, Kathmandu, reported $63 \%$ patients had an ischemic stroke, with the remaining $37 \%$ thehemorrhagic type. $^{8}$

So, we aim to study the clinical profile and risk factors of patients with ischemic stroke presenting to a tertiary care center.

\section{Methods and Materials:}

The study was initiated after receiving approval from the Institutional Review Committee (IRC), Manipal Colleges of Medical Sciences, Pokhara, Nepal. Informed consent was obtained from all study participants.

This is a descriptive cross-sectional study. All the patients presenting to the medicine department who were ready to participate were included in the study. We used a convenient sampling technique. Data collection was done between October 2019 to December 2019.

We designed a questionnaire focusing on the sociodemographic profile of patients. The questions concerned: age, marital status, occupation, education, religion, socio-economic status, history of medical illness, and other personal histories.

The necessary history used for the study was taken from the patient and/or caregivers by the language they understood. Clinical presentation and all relevant lab investigations had been recorded.

Descriptive analysis has been done using The Statistical Package for Social Science software (IBM SPSS Statistics 21, Chicago, USA) for analysis.

\section{Results:}

Altogether 50 participants were included in the study. Among them, 58\% aged 65 and above, 36\% belonged between 45 to 65 years and $6 \%$ belonged to age younger than 45 years. Most of them were male $(62 \%)$. Other socio-demographic variables are shown in (Table 1).
Table 1: Socio-demographic profile of stroke patients

\begin{tabular}{|c|c|c|c|}
\hline \multicolumn{2}{|c|}{ Variables } & \multirow{2}{*}{$\begin{array}{c}\mathbf{N}=\mathbf{5 0} \\
3\end{array}$} & \multirow{2}{*}{$\begin{array}{c}\% \\
6\end{array}$} \\
\hline Age & $<45$ & & \\
\hline & 45 to 65 & 18 & 36 \\
\hline & $>65$ & 29 & 58 \\
\hline \multirow[t]{2}{*}{ Sex } & Male & 31 & 62 \\
\hline & Female & 19 & 38 \\
\hline \multirow[t]{2}{*}{ Education } & No formal & 26 & 52 \\
\hline & Formal & 24 & 48 \\
\hline \multirow[t]{2}{*}{ Residence } & Rural & 28 & 56 \\
\hline & Urban & 22 & 44 \\
\hline \multirow{2}{*}{$\begin{array}{l}\text { Family } \\
\text { Income per } \\
\text { month }\end{array}$} & $<15000 \mathrm{NRS}$ & 32 & 64 \\
\hline & $\begin{array}{l}15000 \mathrm{NRS} \text { and } \\
\text { above }\end{array}$ & 18 & 36 \\
\hline
\end{tabular}

Among the risk factors, the most common risk factor was hypertension (50\%) followed by smoking $(46 \%)$. Other risk factors in descending orders were family history of stroke (28\%), diabetes (24\%), arrhythmia (24\%), dyslipidemia (18\%), and the least common was a coronary disease (12\%) (Table 2).

Among the clinical presentation aphasia (46\%) was the most common presentation, followed by vomiting (30\%), facial palsy (30\%), loss of consciousness $(20 \%)$, seizure $(16 \%)$, headache $(10 \%)$, gait abnormality $(6 \%)$ and eye gaze impairment (6\%). Headache and speech abnormality were significantly associated with different types of stroke (Table 3). 


\section{Discussion:}

The present study outlined the profile of a patient with stroke on different demographic aspects, clinical characteristics, and risk factors.

Table 2: Common risk factors of stroke

\begin{tabular}{|c|c|c|c|}
\hline \multicolumn{2}{|c|}{ Variables } & \multirow{2}{*}{$\begin{array}{c}\mathbf{N}=\mathbf{5 0} \\
25\end{array}$} & \multirow{2}{*}{$\begin{array}{l}\% \\
50\end{array}$} \\
\hline Hypertension & Present & & \\
\hline & Absent & 25 & 50 \\
\hline \multirow[t]{2}{*}{ Diabetes } & Present & 12 & 24 \\
\hline & Absent & 38 & 76 \\
\hline \multirow{2}{*}{$\begin{array}{l}\text { Coronary artery } \\
\text { disease }\end{array}$} & Present & 6 & 12 \\
\hline & Absent & 44 & 88 \\
\hline \multirow[t]{2}{*}{ Smoking } & Present & 23 & 46 \\
\hline & Absent & 27 & 54 \\
\hline \multirow[t]{2}{*}{ Arrhythmia } & Absent & 12 & 24 \\
\hline & Present & 38 & 76 \\
\hline \multirow[t]{2}{*}{ Dyslipidaemia } & Present & 9 & 18 \\
\hline & Absent & 41 & 82 \\
\hline \multirow{2}{*}{$\begin{array}{l}\text { Family history of } \\
\text { stroke }\end{array}$} & Present & 14 & 28 \\
\hline & Absent & 36 & 72 \\
\hline
\end{tabular}

In our study, most of the patients $(58 \%)$ belonged to age 65 years and above, where the mean age was $67 \pm 13$ years. It is well established that the risk of stroke increases with age, the incidence doubles with each decade after the age of 45 years and over $70 \%$ of all strokes occur above the age of $65 .^{9}$ The reason behind this might be the multi-morbidity, as the presence of two or more chronic conditions are common phenomena in elderly people; and higher incidence estimated to be $89 \%$ for those aged $\geq 65$ years and $60 \%$ for those aged $<65$ years. ${ }^{10}$
Table 3: Clinical presentation of participants and its significance with stroke type

\begin{tabular}{|c|c|c|c|c|}
\hline \multicolumn{2}{|c|}{ Variables } & \multirow{2}{*}{$\begin{array}{c}\text { Ischemi } \\
\text { c stroke } \\
\text { N }\end{array}$} & \multirow{2}{*}{$\begin{array}{c}\text { Haemor } \\
\text { rhagic } \\
\text { Stroke } \\
\text { N }\end{array}$} & \multirow{2}{*}{$\begin{array}{c}\chi^{2} \\
\text { df } \\
\text { p-value }\end{array}$} \\
\hline & & & & \\
\hline \multirow[t]{2}{*}{ Headache } & Present & 2 & 3 & 9.76 \\
\hline & Absent & 41 & 4 & 0.002 \\
\hline \multirow[t]{2}{*}{ Speech } & Aphasia & 18 & 6 & $\begin{array}{l}4.6 \\
1\end{array}$ \\
\hline & Normal & 25 & 1 & 0.03 \\
\hline
\end{tabular}

In our study, stroke was more prevalent among male compared to female patients. Similar findings were also reported in different studies throughout the world. One systematic review conducted by Appelros $\mathrm{P}$ et al showed male stroke incidence rate was $33 \%$ higher and stroke prevalence was $41 \%$ higher than the females, with large variations between age and population. ${ }^{11}$ Similarly, one multicentre study from Asia showed a male to female ratio of 1.9 in stroke patients. ${ }^{12}$ One possible explanation of this result might be, lifetime exposure to ovarian estrogens may protect against ischemic stroke, mainly in non-cardio embolic type. ${ }^{13}$ Second factor may simply be blood pressure. Studies have shown that blood pressure values are higher in men than women of similar ages. $^{14}$

In our study, among stroke patients $64 \%$ belonged to a low socioeconomic status which is comparable with a study from Cox AM et al. In a review article in 2006 Cox AM et al showed consistent evidence of an inverse relationship between socioeconomic status and stroke incidence. ${ }^{15}$

There are many proposedhypotheses for the link between socioeconomic status and the risk of stroke incidence. One of them is the fetal origins hypothesis, which suggests that stroke in adulthood is associated with poor nutrition in utero and infancy. ${ }^{16}$ 
The Association of education level with stroke risk is consistent with the findings from many existing studies. $^{17,18}$ However, we did not observe an increase in stroke risk with decreasing education level. We did not observe major rural/urban differences in risk factor prevalence in our study, but in literature, we found many studies with rural/urban disparities. The CANHEART (Cardiovascular Health in Ambulatory Care Research Team) a large cohort study of over 6 million people from Canada reported that rural residents were less likely than urban ones to be screened for diabetes mellitus and hyperlipidemia and less likely to achieve diabetes mellitus control and there is a higher stroke incidence and mortality in rural compared with urban areas. ${ }^{19}$

The main findings from this study were the substantial presence of traditional risk factors in our patients. Hypertension was documented in 50\% of patients and was the most common risk factor followed by smoking (46\%). A similar finding was found in a multi-city study from Asia which documented $47.2 \%$ of patients having hypertension and $38.8 \%$ had smoking as a risk factor. ${ }^{12}$

We found $24 \%$ of patients having diabetes which was comparable with meta-analysis done by Lau $\mathrm{LH}$ et al. who reported a prevalence of $28 \%$. Diabetes is a well-established risk factor for stroke. It can cause pathologic changes in blood vessels and can lead to stroke if cerebral vessels are directly affected. Furthermore, uncontrolled glucose levels are associated with higher mortality and post-stroke poorer outcomes. ${ }^{12,20}$

The review article Stroke Epidemiology in South, East, and South-East Asia highlighted that in most countries, high or low frequencies of occurrence are observed consistently across all risk factors for that country. In that study, hypercholesterolemia was seen in Japan, Singapore, and Brunei (low in Nepal, Timor Leste, and DPR Korea); inactivity in Malaysia (low in Nepal). ${ }^{21}$ We also found similar findings, dyslipidemia was less common compared to hypertension, smoking, and diabetes. Familial history of stroke has been hypothesized as a risk factor for stroke. ${ }^{22} \mathrm{We}$ found $28 \%$ of patients having a family history of stroke in our study. Arrhythmia (24\%) and coronary artery disease $(12 \%)$ are other risk factors found in our study.
These findings were expected because these factors were found to be associated with an increase of stroke in the past studies. ${ }^{23}$

Various studies in the past have documented aphasia in 22.7-67.6\% of the stroke cases. ${ }^{24}$ In our study, aphasia was present in $46 \%$ of the cases, which was the most common clinical presentation. Hemorrhagic stroke was significantly associated with the occurrence of aphasia.

Another clinical presentation significantly associated with hemorrhagic stroke in our study was a headache, however, in literature, we found mixed result regarding the association of this clinical presentation with stroke type. ${ }^{24,25}$

The study was associated with some limitations and drawbacks. First, this study was a hospitalbased study rather than a longitudinal communitybased study that could prone to selection bias. Secondly, a small sample size of our study could not be generalized to the general population. Thirdly, we could not consider minor or uncommon risk factors for stroke in our study.

Previous studies suggest that the quality of life and functional outcome to be poorer among females because of the older age of onset and tendency to suffer a more severe stroke as compared to male. ${ }^{7,8}$, ${ }^{9}$ But our study showed there to be a better outcome among female patients than male patients with the p-value of 0.001 on the 30 days follow up. It could be possible due to the presence of ischemic CVA population only in our study vs. all stroke patients in previous studies. The other reason could be due to a shorter follow up period of 30 days in our study vs. a longer follow up period in other studies. However, the female gender was not an independent factor for a negative outcome. ${ }^{14}$ Also the pathophysiology of ischemic stroke may be different between male and female population. ${ }^{14}$

There are various risk factors associated with stroke incidence out of which it is further categorized as modifiable and non-modifiable risk factors as tabulated in Table 4. Modification of these risk factors is associated with decreased incidence of stroke. ${ }^{10}$ Modification of these risk factors can be achieved via pharmacotherapy (antihypertensive, lipid-lowering medications, anti- 
platelets, and anti-coagulants) ${ }^{11}$ and lifestyle modifications(exercise, reduced dietary sodium and fat intake and weight loss). ${ }^{12}$ The gradual accumulation of modifiable risk factors increases the incidence of stroke over time. ${ }^{13}$ In our study, we studied Hypertension, Type II DM, Dyslipidemia, CAD, Smoking, Family history, Prior Stroke, AF, Carotid Stenosis, Polycythemia, VHD, PVD, ECG and Structural Heart Changes. Out of which there was statistical significance between HTN, DM, Coronary Artery Disease, Dyslipidemia, AF, and Carotid Stenosis as shown in table $\mathbf{1}$ and $\mathbf{2}$.

High blood pressure is the most prevalent modifiable risk factor for stroke. ${ }^{15}$

However, our study did not find any statistical significance between smoking, family history ofstroke, polycythemia, valvular heart disease, peripheral vascular disease, structural heart changes, and history of prior stroke. This could bepossible due to the smaller sample size in our study.

\section{Conclusion:}

The majority of the patients were males, old aged, rural residents, uneducated, and low socioeconomic status. The most common risk factor identified was hypertension and the most common clinical presentation was speech abnormality. Headache and speech abnormality is the significant clinical presentation associated with stroke type. Stroke is very prevalent in the population; so, large scale community health campaigns should be launched focusing on community education regarding risk factors of stroke.

\section{References:}

1. Global Health Estimates. Geneva: World Health Organization; 2012. Available from: http://www.who.int/healthinfo/global_burden_dise ase/en/ [cited 2016 June 1].

2. Feigin VL, Forouzanfar MH, Krishnamurthi R, Mensah GA, Connor M, Bennett DA, et al.; Global Burden of Diseases, Injuries, and Risk Factors Study 2010 (GBD 2010) and the GBD Stroke Experts Group. Global and regional burden of stroke during 1990-2010: findings from the Global Burden of Disease Study 2010. Lancet. 2014 Jan 18;383(9913):245-54

egneuro, Volume 02, Issue 02, 2020
3. Strong K, Mathers C, Bonita R. Preventing stroke: saving lives around the world. Lancet Neurol. 2007 Feb;6(2):1827.

4. Mozaffarian D., Benjamin E. J., Go A. S., Arnett D. K., Blaha M. J., Cushman M., et al. Heart disease and stroke statistics--2015 update: a report from the American Heart Association. Circulation. 2015;131(4): e29-e322.

5. Bennett D. A., Krishnamurthi R. V., Barker-Collo S., et al. The global burden of ischemic stroke: Findings of the GBD 2010 study. Global Heart. 2014;9(1):107-112.

6. Pandit A, Arjyal A, Farrar J, Basnyat B. Nepal. Pract Neurol 2006; 6:129-33.

7. Devkota KC, Thapamagar SB, Malla S. Retrospective analysis of stroke and its risk factors at Nepal Medical College Teaching Hospital. Nepal Med Coll J 2006; 8:269-75

8. Oli KK, Agarwal JP. Critical review of stroke. J Inst Med 2001; 23:68- 71 .

9. Lloyd-Jones D, Adams RJ, Brown TM, et al. Heart disease and stroke statistics--2010 Update: A Report From the American Heart Association. Circulation. 2010;121: e46e215.

10. Yousufuddin M, et al. J Stroke Cerebrovasc Dis. 2017; 26:1239-48

11. Appelros P, Stegmayr B, Terént A. Sex differences in stroke epidemiology: a systematic review. Stroke. 2009;40(4):1082-1090.

12. Kay Sin Tan, Jose C. Navarro, Ka Sing Wong, Yi Ning Huang, Hou Chang Chiu, Niphon Poungvarin, et al. Clinical profile, risk factors and etiology of young ischemic stroke patients in Asia: a prospective, multicentre, observational, hospital-based Study in eight cities. Neurol Asia. 2014;19(2):117-27.

13. de Lecin ana MA, Egido JA, Ferna'ndez C, Martinez-Vila E, Santos S, Morales A, Martinez E, Pareja A, A' lvarezSabin J, Casado I. Risk of ischemic stroke and lifetime estrogen exposure. Neurology. 2007;68: 33-38.

14. Wiinberg N, Høegholm A, Christensen HR, Bang LE, Mikkelsen KL, Nielsen PE, Svendsen TL, Kampmann JP, Madsen NH, Bentzon MW. 24-h ambulatory blood pressure in 352 normal Danish subjects, related to age and gender. Am J Hypertens. 1995; 8:978 -986.

15. Cox AM, McKevitt C, Rudd AG, Wolfe CDA. Socioeconomic status and stroke. Lancet Neurol 2006; 5: 181-88.

16. Martyn CN, Barker DJP, Osmond C. Mothers' pelvic size, fetal growth, and death from stroke and coronary heart disease in men in the UK. Lancet 1996; 348: 1264-68.

17. Andersen KK, Steding-Jessen M, Dalton SO, et al. Socioeconomic position and incidence of ischemic stroke in Denmark 2003-2012. A nationwide hospital-based study. J Am Heart Assoc 2014;3: e000762 10.

18. Avendano M, Boshuizen HC, Schellevis FG, et al. Disparities in stroke preventive care in general practice did not explain socioeconomic disparities in stroke. $\mathrm{J}$ Clin Epidemiol 2006; 59:1285-94.

19. Kapral MK, Austin PC, Jeyakumar G, et al. Rural-Urban Differences in Stroke Risk Factors, Incidence, and Mortality in People With and Without Prior Stroke. Circ Cardiovasc Qual Outcomes. 2019;12(2): e004973.

20. Lau LH, Lew J, Borschmann K, Thijs V, Ekinci EI. Prevalence of diabetes and its effects on stroke outcomes: 
A meta-analysis and literature review. J Diabetes Investig. 2019;10(3):780-792. doi:10.1111/jdi.12932.

21. Venketasubramanian N, Yoon BW, Pandian J, Navarro JC. Stroke Epidemiology in South, East, and South-East Asia: A Review [published correction appears in J Stroke. 2018 Jan;20(1):142]. J Stroke. 2017;19(3):286-294. doi:10.5853/jos.2017.00234

22. Seshadri S, Beiser A, Pikula A, Himali JJ, Kelly-Hayes M, Debette $S$, et al. Parental occurrence of stroke and risk of stroke in their children: the Framingham study.Circulation. 2010; 121:1304-1312.

23. Coca A, Messerli FH, Benetos A, et al. Predicting stroke risk in hypertensive patients with coronary artery disease: a report from the INVEST. Stroke. 2008;39(2):343-348.

24. Bohra V, Khwaja GA, Jain S, Duggal A, Ghuge VV, Srivastava A. Clinicoanatomical correlation in stroke related aphasia. Ann Indian Acad Neurol. 2015;18(4):424429.

25. Ojaghihaghighi S, Vahdati SS, Mikaeilpour A, Ramouz A. Comparison of neurological clinical manifestation in patients with hemorrhagic and ischemic stroke. World J Emerg Med. 2017;8(1):34-38. 